\title{
Psychometric properties of the Big Five Inventory in a Chinese sample of smokers receiving cessation treatment: A validation study
}

\author{
Doris YP Leung ${ }^{1}$, Eliza ML Wong', Sophia SC Chan², TH Lam³ \\ 1. Nethersole School of Nursing, The Chinese University of Hong Kong, China. 2. School of Nursing, The University of Hong \\ Kong. 3. School of Public Health, The University of Hong Kong, China.
}

Correspondence: Leung Doris YP. Address: 8/F, Esther Lee Building, The Chinese University of Hong Kong, Shatin, Hong Kong, China. Email: dorisleung@cuhk.edu.hk.

Received: J une 24, 2012

DOI : 10.5430/jnep.v3n6p1
Accepted: July 18, $2012 \quad$ Online Published: December 26, 2012

URL: http://dx.doi.org/10.5430/jnep.v3n6p1

\section{Abstract}

Background: Some personality traits were found to be relevant to engagement in smoking. Examination of associations between personality traits and behaviours in smoking and cessation will guide the development of effective preventive and cessation interventions. The objective of this study was to evaluate the factor structure and reliability of a Chinese version of the Big Five Inventory (BFI) for assessing the five personality dimensions of extraversion, agreeableness, conscientiousness, neuroticism and openness to experience in adults who had a smoking habit.

Methods: 1173 Chinese smokers who had received smoking cessation intervention at a smoking cessation health centre in Hong Kong from 21 August 2000 to January 2002 were followed-up by telephone between February and August 2008. Participants completed a questionnaire including the 44-item BFI and perceived health status. A total of 480 (41\%) participants completed the survey and 439 questionnaires without missing were analysed. The factor structure of the BFI was assessed by confirmatory factor analysis, reliability by Cronbach alpha and concurrent validity by personality scores by gender and relationship with perceived health. The convergent and discriminant validity of the reduced version of BFI was compared to the original version using the mulittrait-multimethod matrix approach.

Results: Confirmatory factor analyses revealed that the five-factor structure provided an acceptable fit after removing 15 items which did not contribute to their corresponding factors. The reduced 29-item BFI had internal reliability estimates ranged from 0.69 for agreeableness to 0.81 for neuroticism. Women scored significantly higher in neuroticism and lower in openness to experience. All the correlations of the five personality traits with perceived health were in the expected directions and statistically significant except openness to experience. The four requirements of convergent and discriminant validity of the reduced 29-item BFI were met.

Conclusions: These results showed that the satisfactory psychometric properties of the Chinese version of BFI with modifications; suggesting that the Chinese translation of the abbreviated 29-item BFI could be a useful and practical tool in measuring personality traits among Chinese adults had a smoking habit.

\section{Key words}

Personality, Big five Inventory, Chinese smokers, Construct validity, Reliability, Convergent and discriminant validity, Confirmatory factor analysis 


\section{Introduction}

Smoking is the biggest preventive cause of death. China has the world's largest number of smokers $(57.4 \%$ in males and $2.6 \%$ in females $)^{[1]}$ but smoking cessation is uncommon. Hong Kong is the most westernised city of China with the lowest smoking prevalence of about $14 \%$ (24.5\% male and $4.0 \%$ female $)^{[2]}$ and better availability of smoking cessation service, yet smoking kills about 6000 people per year, accounting for about one-fifth of all deaths ${ }^{[3]}$.

Smoking cessation should be a high priority as it will result in health gain and reduced medical burden and premature deaths due to smoking attributable diseases. Smoking cessation programs are increasingly concerned with matching interventions according to some relevant, predictive dimension prior to treatment to meet individuals' needs, such as the degree of nicotine dependency (e.g. dose of nicotine replacement therapy), and stage of readiness to change ${ }^{[4,5]}$. In the context of treatment, it is thus important to investigate how individual differences, variables or personality traits in particular are associated with quitting behaviours as individuals may vary in their successes with quitting smoking and in their responses to treatment. Understanding such relationships can then be useful for screening purposes ${ }^{[6]}$, which could inform the development of matching treatments and hence should lead to improvement in both treatment outcome and cost-effectiveness.

Research grounded in the five-factor taxonomy of personality ${ }^{[7]}$ (extraversion, neuroticism, agreeableness, conscientiousness, and openness to experience) suggests that some personality traits may be particularly relevant to engagement in smoking and hence will provide insight into smoking behavior and smoking cessation ${ }^{[8]}$. A growing literature suggests that some personality traits may be particularly relevant to engagement in smoking. Previous cross-sectional studies have indicated that smokers tend to score significantly higher in extraversion and neuroticism than non-smokers ${ }^{[9,10]}$. Longitudinal studies also provide evidence that individual differences in extraversion and neuroticism may be important risk factors in smoking initiation ${ }^{[11-13]}$.

The five-factor model is a useful framework to measure human personality ${ }^{[14,15]}$, organising personality into five broad dimensions: extraversion, agreeableness, conscientiousness, neuroticism and openness to experience ${ }^{[16]}$. The Big Five Inventory (BFI) was developed to provide a short, flexible and easy to understand assessment of these five dimensions for studies which focus on the five broad dimensions instead of individual facets ${ }^{[17]}$. The original BFI consists of 44 items (BFI-44), shorter than other commonly used tools measuring personality such as the 60 -item form of the NEO-PI-R ${ }^{[18]}$ and the IPIP Big-Five 50-item factor markers ${ }^{[14]}$. Recently, the BFI was reduced to a 10-item abbreviated version (BFI-10), with two items, one positive and one negative, per factor ${ }^{[19]}$, but the stability of this short version of the BFI might be in question as a measure of personality trait ${ }^{[20]}$. Both English and Spanish versions of the original BFI-44 were shown to have good reliability and acceptable factorial structure, and convergent and discriminant validity ${ }^{[16,21,22]}$. A recent cross-cultural study also showed the instrument had acceptable reliability and factor structure across 56 nations in 10 world regions ${ }^{[23]}$. The BFI-44 has been used in a wide range of studies including education, language use, and clinical research ${ }^{[24-27]}$, and also as a criterion variable for validating the IPIP Big-Five factor markers in a study conducted in China ${ }^{[28]}$. But none of these studies reported the factor structure of the BFI-44 in their samples.

It has been suggested that examining the associations between personality traits and smoking and cessation behaviours will provide insights leading to the development of effective prevention and cessation interventions ${ }^{[29,30]}$. The BFI appears to offer substantial promise as a measure of personality traits, but most validation studies of the scale have only used undergraduate samples, which might have limited its applications to health behaviour research, in particular among smokers. There is an evident need to validate the Chinese version of the BFI-44 in the case of smokers, as China has the largest number of smokers in the world ${ }^{[1]}$.

Therefore, the purpose of this study is to examine the psychometric properties of the BFI-44 in a Chinese sample of smokers seeking cessation treatment in Hong Kong. 


\section{Methods}

\subsection{Procedures}

This is a cross-sectional study which followed up 1,173 Chinese smokers who had attended a smoking cessation health centre (SCHC) in Hong Kong from 21 August 2000 to January 2002. The telephone survey was conducted from February to August 2008. An invitation letter was first mailed to all the participants with available addresses to remind them briefly about the service they had received seven years ago at the SCHC in the hospital, and explain the purpose, procedures and research team of the study. One week later, an experienced trained interviewer contacted the participants via telephone. After obtaining verbal consent, the interviewer administered the questionnaire. Any participants who could not be reached after eight calls at different times of the day were classified as lost to follow-up. We planned to contact about 150 participants per month and complete the whole follow-up survey within nine months. Three lucky draws, each with two prizes of HK $\$ 1,000$, were held every three months in the nine-month data collection period to boost the participation rate. The study was approved by the institutional review board of the university on 28 January 2008.

\subsection{Participants}

A total of 480 out of the original 1,173 smokers (41\%) completed the follow-up survey, yielding a response rate of $41 \%$; 152 refused, 522 were lost to follow-up and 19 were reported dead. Among the 480 participants, $83.8 \%$ were male, $33.5 \%$ were married and $24.4 \%$ had completed secondary school education. Their mean age was 40.6 years $(\mathrm{SD}=12.0$; range $=$ 12 - 88 years) and mean duration of smoking was 22 years $(\mathrm{SD}=11.7$ years $)$ at baseline, and $43.1 \%$ reported quitting for at least 30 days at the follow-up survey.

\subsection{Measures}

The Big Five Inventory consists of 44 items measuring five trait dimensions of personality - extraversion ( 8 items), agreeableness ( 9 items), conscientiousness ( 9 items), neuroticism ( 8 items) and openness to experience ( 9 items) - and uses a 5-point Likert scale from $1=$ 'strongly disagree' to $5=$ 'strongly agree'. The instrument was first translated into Chinese by an experienced researcher with a first degree in translation and then checked by the research team, who were fluent in both English and Chinese. Care was taken to ensure each item translated retained a meaning as close as possible to the original version by means of a back translation process. One item was used to measure perceived health status in the past three months using a 5-point Likert scale ranged from $1=$ 'very poor' to $5=$ 'very good'.

\subsection{Data analysis}

Confirmatory factor analysis (CFA) was used to assess the factor structure of the BFI among the 439 participants who completed all 44 items of the BFI. A five-factor model with items corresponding to each of the five trait dimensions as proposed by the instrument developers was fitted to the covariance matrix of the BFI items. According to the recommendations for personality data ${ }^{[31,32]}$, we evaluated the model goodness-of-fit using (1) robust root mean square error of approximation (R-RMSEA) with a 90\% confidence interval for non-normal data, (2) standardised root mean squared residuals (SRMR) and (3) standardised factor loadings. A good fit to the data was indicated by SRMR $<0.08$, R-RMSEA $<0.06^{[33]}$ and standardised factor loadings $\geq 0.4^{[34]}$. If the model did not fit the data well, it was re-specified by deleting items which did not contribute to their corresponding component, i.e. the items with standardised factor loadings $<0.4$. The re-specified model was then assessed for goodness-of-fit with the data. If the re-specified model still did not fit the data well, the reduction procedure was repeated and the re-specified model assessed again. Model chi-square test statistics and associated degrees of freedom, and a robust comparative fit index were also reported for completeness, although they were not used for model evaluation. Once an acceptable model had been achieved, the reliability of each of the five personality trait dimensions was assessed by Cronbach's alpha and concurrent validity by correlation with current perceived health status. For each of the five personality dimensions, the mean score was computed by averaging the corresponding items in that dimension. Gender differences in each of the five personality traits were compared using 
Mann-Whitney tests. Moreover, the convergent and discriminant validity of the reduced BFI obtained in the above CFA procedure were compared with the original BFI-44 by computing the multitrait-multimethod matrix ${ }^{[35]}$. All CFAs were performed using EQS $6.0^{[36]}$ with the robust correction to maximum likelihood estimation procedure as the data were found to be non-normal (normalised estimate $=48.14)^{[37]}$. Cronbach's alpha, Pearson's correlation and Mann-Whitney tests were computed by SPSS18.0. All statistical tests were two-tailed, and results were considered significant at $p<0.05$.

\section{Results}

\subsection{Confirmatory factor analysis and reliability}

The CFA results revealed that the 5-factor model (Model 1) provided a poor fit with the data of the full 44-item BFI (see Table 1). Inspection of standardised factor loadings of items in Model 1 (see Table 2) revealed that 13 out of 44 (two for extraversion, three for agreeableness, three for conscientiousness, one for neuroticism and four for openness to experience) were $<0.4$, and these were therefore deleted from the model. The re-specified five-factor model with the remaining 31 items of the BFI (Model 2) provided an acceptable fit with the data, but standardised factor loadings of two items (one for agreeableness and one for conscientiousness) were still $<0.4$. The reduction procedure was thus repeated after deleting these two items and formed Model 3 with the remaining 29, which gave an acceptable fit with the data, all standardised factor loadings being $>0.4$. Except for a large positive correlation between agreeableness and conscientiousness $(0.81)$, and a non-significant negative correlation between neuroticism and openness to experience (-0.06), the estimated factor correlations between the five personality traits in Model 3 were moderate in magnitude, suggesting the five personality traits were distinct and correlated factors in general. The reliability of the five personality dimensions of the reduced 29-item BFI was satisfactory, with the Cronbach's alpha values of the five dimensions ranging from 0.69 to $0.81^{[38]}$.

Table 1. Results of confirmatory factor analysis of model testing $(\mathrm{n}=439)$

\begin{tabular}{llllll}
\hline & R- $\chi^{2}$ & df & R-CFI & SRMR & R-RMSEA \\
\hline Model 1 (44-item) & 2311.7 & 892 & 0.642 & 0.094 & $0.062(0.059-0.065)$ \\
Model 2 (31-item) & 1011.7 & 424 & 0.800 & 0.080 & $0.057(0.052-0.062)$ \\
Model 3 (29-item) & 813.8 & 367 & 0.835 & 0.075 & $0.054(0.049-0.058)$ \\
\hline
\end{tabular}

Note. $\mathrm{R}-\chi 2$ = Robust model chi-square statistic; $\mathrm{df}=$ degree of freedom; R-CFI = Robust Comparative Fit Index; SRMR = standardised root mean squared residuals; R-RMSEAR = robust root mean square error of approximation.

Table 2. Standardised factor loadings for alternative models of the BFI $(\mathrm{n}=439)$

\begin{tabular}{llll}
\hline & $\begin{array}{l}\text { Model 1 } \\
\mathbf{( 4 4} \text { items) }\end{array}$ & $\begin{array}{l}\text { Model 2 } \\
\text { (31 items) }\end{array}$ & $\begin{array}{l}\text { Model 3 } \\
\text { (29 items) }\end{array}$ \\
\hline Extraversion & & & \\
1. Is talkative & 0.652 & 0.658 & 0.658 \\
6. Is reserved (-) & 0.022 & -- & -- \\
11. Is full of energy & 0.514 & 0.515 & 0.518 \\
16. Generates a lot of enthusiasm & 0.495 & 0.497 & 0.493 \\
21. Tends to be quiet (-) & -0.504 & -0.504 & -0.501 \\
26. Has an assertive personality & -0.043 & --- & --- \\
31. Is sometimes shy, inhibited (-) & -0.438 & -0.436 & -0.436 \\
36. Is outgoing, sociable & 0.758 & 0.759 & 0.760 \\
Cronbach's alpha & & & 0.72 \\
\hline
\end{tabular}


Table 2. (Continued.)

\begin{tabular}{|c|c|c|c|c|}
\hline & $\begin{array}{l}\text { Model 1 } \\
\text { (44 items) }\end{array}$ & & $\begin{array}{l}\text { Model 2 } \\
\text { (31 items) }\end{array}$ & $\begin{array}{l}\text { Model } 3 \\
\text { (29 items) }\end{array}$ \\
\hline \multicolumn{5}{|l|}{ Agreeableness } \\
\hline 2. Tends to find fault with others (-) & -0.179 & & --- & --- \\
\hline 7. Is helpful and unselfish with others & 0.520 & & 0.556 & 0.589 \\
\hline 12. Starts quarrels with others (-) & -0.235 & & --- & --- \\
\hline 17. Has a forgiving nature & 0.538 & & 0.528 & 0.552 \\
\hline 22. Is generally trusting & 0.596 & & 0.618 & 0.619 \\
\hline 27. Can be cold and aloof (-) & -0.462 & & -0.390 & --- \\
\hline 32. Is considerate and kind to almost everyone & 0.566 & & 0.575 & 0.583 \\
\hline 37. Is sometimes rude to others (-) & -0.347 & & --- & --- \\
\hline 42. Likes to cooperate with others & 0.491 & & 0.517 & 0.511 \\
\hline Cronbach's alpha & & & & 0.69 \\
\hline \multicolumn{5}{|l|}{ Conscientiousness } \\
\hline 3. Does a thorough job & 0.465 & & 0.494 & 0.487 \\
\hline 8. Can be somewhat careless (-) & -0.274 & & --- & --- \\
\hline 13. Is a reliable worker & 0.497 & & 0.571 & 0.576 \\
\hline 18. Tends to be disorganised (-) & -0.372 & & --- & --- \\
\hline 23. Tends to be lazy (-) & -0.478 & & -0.386 & --- \\
\hline 28. Perseveres until the task is finished & 0.601 & & 0.608 & 0.607 \\
\hline 33. Does things efficiently & 0.608 & & 0.608 & 0.609 \\
\hline 38. Makes plans and follows through with them & 0.616 & & 0.604 & 0.608 \\
\hline 43. Is easily distracted (-) & -0.378 & & --- & --- \\
\hline Cronbach's alpha & & & & 0.71 \\
\hline \multicolumn{5}{|l|}{ Neuroticism } \\
\hline 4. Is depressed, blue & 0.627 & & 0.624 & 0.623 \\
\hline 9. Is relaxed, handles stress well (-) & -0.463 & & -0.434 & -0.432 \\
\hline 14. Can be tense & 0.713 & & 0.736 & 0.738 \\
\hline 19. Worries a lot & 0.684 & & 0.695 & 0.695 \\
\hline 24. Is emotionally stable, not easily upset (-) & -0.580 & & -0.555 & -0.553 \\
\hline 29. Can be moody & 0.605 & & 0.600 & 0.597 \\
\hline 34. Remains calm in tense situations (-) & -0.340 & & --- & --- \\
\hline 39. Gets nervous easily & 0.718 & & 0.733 & 0.735 \\
\hline Cronbach's alpha & & & & 0.81 \\
\hline \multicolumn{5}{|l|}{ Openness to experience } \\
\hline 5. Is original, comes up with new ideas & 0.694 & & 0.677 & 0.679 \\
\hline 10. Is curious about many different things & 0.421 & & 0.440 & 0.442 \\
\hline 15. Is ingenious, a deep thinker & 0.527 & & 0.553 & 0.552 \\
\hline 20. Has an active imagination & 0.653 & & 0.659 & 0.659 \\
\hline 25. Is inventive & 0.781 & & 0.775 & 0.774 \\
\hline 30. Values artistic, aesthetic experiences & 0.399 & & --- & --- \\
\hline 35. Prefers work that is routine (-) & -0.060 & & --- & --- \\
\hline 40. Likes to reflect, play with ideas & 0.505 & & 0.531 & 0.530 \\
\hline 41. Has few artistic interests (-) & -0.171 & & --- & --- \\
\hline 44. Is sophisticated in art, music or literature & 0.285 & & --- & --- \\
\hline Cronbach's alpha & & & & 0.77 \\
\hline \multicolumn{5}{|l|}{ Factor correlations in Model 3} \\
\hline A & & $\mathrm{C}$ & $\mathrm{N}$ & $\mathrm{O}$ \\
\hline 0.557 & & 0.501 & -0.396 & 0.586 \\
\hline A & & 0.812 & -0.234 & 0.446 \\
\hline $\mathrm{C}$ & & & -0.288 & 0.542 \\
\hline $\mathrm{N}$ & & & & -0.062 \\
\hline
\end{tabular}

Note: $(-)=$ negatively worded item; Bold $=$ standardised factor loading $<0.4 ; \mathrm{E}=$ Extraversion; $\mathrm{A}=$ Agreeableness; $\mathrm{C}=$ Conscientiousness; $\mathrm{N}=\mathrm{Neuroticism} ; \mathrm{O}=\mathrm{Openness}$ to experience 


\subsection{Personality scores by gender and relationship with perceived health}

Some gender differences were observed in the mean scores of the personality traits, in particular, women displayed significantly higher scores on neuroticism and lower scores on openness to experience than men, while there was no significant difference in the mean scores for extraversion, agreeableness and conscientiousness (see Table 3). Correlations between the reduced BFI-29 and perceived health status were in the expected directions: neuroticism was negatively and the remaining four were positively correlated with perceived health status. Although small in magnitude, all the correlations were statistically significant except that for openness to experience.

Table 3. Mean scores by sex and correlations with perceived health status $(n=439)$

\begin{tabular}{lllllllll}
\hline & \multicolumn{2}{l}{ Total $(\mathbf{n}=\mathbf{4 3 9})$} & \multicolumn{2}{l}{ Men $(\mathbf{n}=\mathbf{3 6 8})$} & \multicolumn{2}{ll}{ Women $(\mathbf{n = 7 1 )}$} & & \multicolumn{2}{c}{ Perceived health status } \\
\hline Personality trait & M & SD & M & SD & M & SD & p-value & Correlation \\
Extraversion & 3.35 & 0.61 & 3.36 & 0.62 & 3.33 & 0.61 & 0.73 & $0.19^{*}$ \\
Agreeableness & 3.37 & 0.52 & 3.68 & 0.50 & 3.60 & 0.60 & 0.24 & $0.11^{*}$ \\
Conscientiousness & 3.74 & 0.56 & 3.75 & 0.57 & 3.65 & 0.48 & 0.16 & $0.13^{* *}$ \\
Neuroticism & 2.71 & 0.68 & 2.68 & 0.67 & 2.87 & 0.72 & 0.025 & $-0.26^{* *}$ \\
Openness to experience & 3.19 & 0.65 & 3.22 & 0.66 & 3.01 & 0.56 & 0.012 & 0.07 \\
\hline
\end{tabular}

${ }^{*} p<0.05,{ }^{* *} p<0.01$

\subsection{Convergent and discriminant validity of the reduced BFI-29}

Examining the multitrait-multimethod matrix of the scores based on the original BFI-44 and the reduced BFI-29 revealed that all the four requirements for convergent and discriminant validity were met: (1) the validity diagonal values of the five traits between the two methods are sufficiently large ( $>0.82)$ and significantly different from zero, (2) all the validity diagonal values are higher than the corresponding values in the heterotrait-heteromethod triangles $(<0.41),(3)$ all the validity diagonal values are higher than the corresponding values in the heterotrait-monomethod triangles $(<0.57)$, and a similar pattern of trait interrelationship was observed in all of the heterotrait triangles of both the monomethod and heteromethod blocks (see Table 4) ${ }^{[35]}$. The results hence suggest that the reduced BFI-29 shows a good evident of convergent and discriminant validity as compared with the original BFI-44.

Table 4. The multitrait-multimethod matrix of the original BFI-44 and the reduced BFI-29 $(n=439)$

\begin{tabular}{|c|c|c|c|c|c|c|c|c|c|c|c|}
\hline & & \multicolumn{5}{|c|}{ BFI-44 } & \multicolumn{5}{|c|}{ BFI-29 } \\
\hline & & $\mathrm{A}_{1}$ & $\mathrm{~B}_{1}$ & $\mathrm{C}_{1}$ & $\mathrm{D}_{1}$ & $E_{1}$ & $\mathrm{~A}_{2}$ & $\mathrm{~B}_{2}$ & $\mathrm{C}_{2}$ & $\mathrm{D}_{2}$ & $\mathrm{E}_{2}$ \\
\hline \multicolumn{12}{|l|}{ BFI-44 } \\
\hline Extraversion & $\mathrm{A}_{1}$ & (.61) & & & & & & & & & \\
\hline Agreeableness & $\mathrm{B}_{1}$ & .34 & $(.57)$ & & & & & & & & \\
\hline Conscientiousness & $\mathrm{C}_{1}$ & .28 & .47 & $(.33)$ & & & & & & & \\
\hline Neuroticism & $\mathrm{D}_{1}$ & -.33 & -.39 & -.45 & $(.80)$ & & & & & & \\
\hline Openness to experience & $E_{1}$ & .31 & .10 & .19 & -.07 & $(.72)$ & & & & & \\
\hline \multicolumn{12}{|l|}{ BFI-29 } \\
\hline Extraversion & $\mathrm{A}_{2}$ & .95 & .41 & .35 & -.40 & .35 & $(.72)$ & & & & \\
\hline Agreeableness & $\mathrm{B}_{2}$ & .37 & .82 & .43 & -.28 & .20 & .41 & (.69) & & & \\
\hline Conscientiousness & $\mathrm{C}_{2}$ & .32 & .47 & .82 & -.32 & .25 & .37 & .56 & $(.71)$ & & \\
\hline Neuroticism & $\mathrm{D}_{2}$ & -.30 & -.36 & -.39 & .97 & -.05 & -.37 & -.23 & -.26 & $(.81)$ & \\
\hline Openness to experience & $\mathrm{E}_{2}$ & .40 & .19 & .35 & -.13 & .87 & .45 & .34 & .43 & -.08 & $(.77)$ \\
\hline
\end{tabular}

\section{Discussion}

The purpose of the current study was to examine further the factorial validity of the BFI-44 as reported in previous research with university students ${ }^{[21,22]}$, but using a Chinese adult population with a smoking habit. The results show that the psychometric properties of the 29-item abbreviated version of the BFI were generally supported. Confirmatory factor 
analysis revealed an acceptable fit for the 5 -factor model with the Chinese version of the BFI as postulated by its developers, with some modifications. Each of the five dimensions in the 29-item abbreviated version of the BFI also showed a high reliability and significant correlations with perceived health status.

With an exploratory process using confirmatory factor analysis, we found that 29 out of 44 intended items (65.9\%) showed better psychometric properties in respect to their corresponding personality trait scale so that the 15 less satisfactory items (factor loadings $<0.4$ ) were removed. Given the concern about the reluctance of participants to complete a long questionnaire, the testing process is very useful in producing an instrument which is as short as possible, while at the same time including all relevant dimensions and providing a reliable measure of them.

On the other hand, twelve out of these 15 removed items were negatively worded (one out of two in extraversion, all four in agreeableness, all four in conscientiousness, the single one in neuroticism and two out of four in openness to experience), suggesting the participants might have interpreted the positively and negatively worded items differently in the BFI-44. Inclusion of both item types may reduce response bias but it also introduces systematic bias in the form of undesirable components and complicates the factor structure ${ }^{[39]}$. It is possible that the BFI-44, similar to other instruments such as the Rosenberg Self-Esteem Scale ${ }^{[40]}$ and General Health Questionnaire ${ }^{[41]}$, also suffers from the effects associated with negatively worded items. Further studies are warranted to examine whether this is a culture- specific-issue or an inherent problem of the BFI-44.

There were significant correlations and in the expected directions between most dimensions. The correlations between extraversion, agreeableness, conscientiousness and openness to experience were quite strong, exceeding values of 0.4. The correlation of neuroticism and openness to experience, on the other hand, was insignificant, which was also reported in the study by Musek (2007) ${ }^{[42]}$. Nevertheless, these results further confirmed that the five personality dimensions were correlated as expected in the sample of Chinese adults had a smoking habit.

Consistent with a previous study by Löckenhoff et al ${ }^{[43]}$, the five personality traits in the BFI correlated with perceived health status in our sample. In particular, neuroticism had the strongest negative association, then followed by extraversion and conscientious with positive association. Our results also support the finding of Löckenhoff et al's study of no association between perceived health status and openness to experience, providing some evidence for concurrent validity of the abbreviated version of the BFI in our sample.

In this study, we also found that women reported a significantly higher mean score on neuroticism, in line with studies showing that women smoked more for tension reduction/relaxation compared to men ${ }^{[44]}$. The findings on the significantly lower mean score in openness to experience among our female participants was somewhat surprising. Since our sample consisted of participants who had proactively sought smoking cessation counselling, it is possible that smoking women who were willing to try new things or were open to new experience were more likely to look for and receive counselling. The results have thus generated a new research hypothesis in linking personality and motivation for quitting.

\section{Limitations}

There are several limitations of the study. First, the present validation study of the BFI was based on a seven-year follow-up of a cohort of Chinese smokers who had received smoking cessation treatment, and the sample in the current study therefore consisted of both current and ex-smokers and different follow-up time of participants, which may limit the generalisability of our results to the Chinese smoking population as a whole. Since personality traits are believed to be very stable over time, especially among adults ${ }^{[45]}$, the current findings should be generalisable given the large smoking population and that more smoking cessation services are expected to be available in China ${ }^{[46]}$. Second, the use of a single-item measure of perceived health status in the study may include some measurement errors leading to an underestimation of the correlations with other variables ${ }^{[47]}$, thus providing an explanation for its small magnitude in the 
observed correlations with the personality trait scores in the study. Third, reliance on self-reported data may introduce bias due to social desirability or different interpretations of item content (wording effects), especially in the case of the current study where the instrument was administered by an interviewer over the telephone.

\section{Conclusions}

In conclusion, the results of the study with a Chinese smoking sample gave preliminary evidence of a five-factor structure and good reliability of the five dimensions in the BFI after deletion of 15 items. The abbreviated 29-item version of the BFI appears to be a practical instrument for measuring personality traits in a Chinese smoking population. This offers health care professionals who involved in providing smoking cessation interventions to Chinese smokers with a practical and usable instrument. It is recommended that more psychometric studies on the abbreviated 29-item BFI using different languages and data of both self- and peer-ratings to assess inter-rater reliability are needed.

\section{Competing interests}

The authors declare that they have no competing interests.

\section{Authors' contributions}

DL participated in the design of the study, performed the statistical analysis, interpreted the results and drafted the manuscript. EW participated in data collection and critically revised the manuscript. THL participated in the design of the study, and helped to draft and revise the manuscript. SC participated in both design and coordination, and helped to revise the manuscript. All authors read and approved the final manuscript.

\section{Acknowledgements}

The follow-up study was funded by the Small Project Fund, University of Hong Kong, and the original study was funded by The Hong Kong Council on Smoking and Health. We thanked Allan Lau for his support in data collection and Victor Chan for his clerical support.

\section{References}

[1] Yang GH, Ma, JM, Liu N, Zhou LN. Smoking and passive smoking in China, 2002. Chinese Journal of Epidemiology. 2005; 26:77-83. PMid: 15921604

[2] Social Surveys Section. Thematic Household Survey Report No.26: Pattern of Smoking. Hong Kong: Census and Statistics Department 2006.

[3] Lam TH, Ho SY, Hedley AJ, Mak KH, Peto R. Mortality and smoking in Hong Kong: case-control study of all adult deaths in 1998. BMJ 2001; 323:1-6. PMid:11509422 http://dx.doi.org/10.1136/bmj.323.7309.361

[4] Velicer WF, Prochaska JO, Fava JL, Laforge RG, Rossi JS. Interactive versus noninteractive interventions and dose-relationships for stage-matched smoking cessation programs in a managed care setting. Health Psychol 1999; 18:21-28. PMid:9925042 http://dx.doi.org/10.1037/0278-6133.18.1.21

[5] Prochaska JO, Velicer WF, Fava JL, Rossi JS, Tsoh JY. Evaluating a population-based recruitment apporach and a stage-based expert system intervention for smoking cessation. Addict Behav 2001; 26:583-602. http://dx.doi.org/10.1016/S0306-4603(00)00151-9

[6] Caprara GV, Cervone D. Personality: Determinants, dynamics, and potentials. New York: Cambridge University Press 2000. http://dx.doi.org/10.1017/CBO9780511812767

[7] McCrae RR, John OP. An introduction to the five-factor model and its applications. J Pers. 1992; 60:175-215. PMid:1635039 http://dx.doi.org/10.1111/j.1467-6494.1992.tb00970.x

[8] Gilbert DG. Smoking: Individual differences, psychopathology, and emotion. Washington, DC: Taylor \& Francis. 1995.

[9] Munafò MR, Zetteler JI, Clark TG. Personality and smoking status: A meta-analysis. Nicotine Tob Res. 2007; 9(3):405-413. http://dx.doi.org/10.1080/14622200701188851 
[10] Terracciano A, Costa PT. Smoking and the five-factor model of personality. Addiction. 2004; 99:472-481. PMid:15049747 PMCid:2376761 http://dx.doi.org/10.1111/j.1360-0443.2004.00687.x

[11] Audrain-McGovern J, Rodriguez D, Tercyak KP, Cuevas J, Rodgers K, Patterson F. Identifying and characterizing adolescent smoking trajectories. Cancer Epidem Biomar. 2004; 13:2023-2034.

[12] Brook JS, Ning Y, Brook DW. Personality risk factors associated with trajectories of tobacco use. Am J Addiction. 2006; 15:426-433. PMid:17182444 http://dx.doi.org/10.1080/10550490600996363

[13] Harakeh Z, Scholte RH, de Vries H, Engels RC. Association between personality and adolescent smoking. Addict Behav. 2006; 31:232-245. PMid:15953689 http://dx.doi.org/10.1016/j.addbeh.2005.05.003

[14] Goldberg LR. The development of markers for the Big-Five Factor Structure. Psychol Assessment. 1992 ; 4:26-42. http://dx.doi.org/10.1037/1040-3590.4.1.26

[15] McCrae RR, Costa PT Jr. A Five-Factor theory of personality. In Handbook of personality: Theory and research. 2nd edition. LA Pervin, OP John, ed. New York: Guilford, 1999, 139-153.

[16] John OP, Donahue EM, Kentle RL. The Big Five Inventory - Versions 4a and 54. Berkeley, CA: Institute of Personality and Social Research. 1991.

[17] John OP, Hampson SE, Goldberg LR. The basic level in personality-trait hierarchies: Studies of trait use and accessibility in different context. J Pers Soc Psychol. 1991; 60:348-361. PMid:2027078 http://dx.doi.org/10.1037/0022-3514.60.3.348

[18] Costa PT Jr, McCrae RR. Revised NEO Personality Inventory (NEO-PI-R) and NEO Five-Factor Inventory (NEO-FFI) professional manual. Odessa FL: Psychological Assessment Resources. 1992.

[19] Rammstedt B, John OP. Measuring personality in one minute or less: a 10-item short version of the Big Five Inventory in English and German. J Res Pers. 2007; 41:203-212. http://dx.doi.org/10.1016/j.jrp.2006.02.001

[20] Rammstedt B, Goldberg LR, Borg I. The measurement equivalence of Big-Five factor markers for persons with different levels of education. J Res Pers. 2010; 44:53-61. http://dx.doi.org/10.1016/j.jrp 2009.10.005

[21] Benet-Martinez V, John OP. Los Cinco Grandes across cultures and ethnic groups: multitrait multimethod analyses of the Big Five in Spanish and English. J Pers Soc Psychol. 1998; 75(3):729-750. http://dx.doi.org/10.1037/0022-3514.75.3.729

[22] Benet-Martinez V, Waller NG. Further evidence for the cross-cultural generality of the Big Seven factor model: Indigenous and imported Spanish personality constructs. J Pers 2006; 65(3):567-598. http://dx.doi.org/10.1111/j.1467-6494.1997.tb00327.x

[23] Schmitt DP, Allik J, McCrae RR, Benet-Martinez V. The geographic distribution of Big Five personality traits: Patterns and profiles of human self-description across 56 nations. J Cross Cult Psychol. 2007; 38(2):173-212. http://dx.dor.org/10.1177/0022022106297299

[24] Patrick CL. Student evaluations of teaching: effects of the Big Five personality traits, grades and the validity hypothesis. Assessment \& Evaluation in Higher Education. 2011; 36(2):239-249. http://dx.doi.org/10.1080/02602930903308258

[25] Wagerman SA, Funder DC. Acquaintance reports of personality and academic achievement: a case for conscientiousness. J Res Pers. 2007; 41:221-229. http://dx.doi.org/10.1016/j.jrp.2006.03.001

[26] Lee CH, Kim K, Seo YS, Chung CK. The relations between personality and language use. J Gen Psychol. 2007; 134(4):405-413. PMid:18183737 http://dx.doi.org/10.3200/GENP.134.4.405-414

[27] Paine P, Kishor J, Worthen SF, Gregory LJ, Aziz Q. Exploring relationships for visceral and somatic pain with autonomic control and personality. Pain. 2009; 144(3):236-244. PMid:19398272 http://dx.doi.org/10.1016/j.pain.2009.02.022

[28] Zheng L, Goldberg LR, Zheng Y, Zhao Y, Tang Y, Liu L. Reliability and concurrent validation of the IPIP Big-Five factor markers in China: consistencies in factor structure between Internet-obtained heterosexual and homosexual samples. Pers Indiv Differ. 2008; 45:649-654. PMid:20383283 PMCid:2851096 http://dx.doi.org/10.1016/j.paid.2008.07.009

[29] Gilbert DG. Smoking: Individual differences, psychopathology, and emotion. Washington DC: Taylor \& Francis. 1995.

[30] Staiger PK, Kambouropoulos N, Dawe S. Should personality traits be considered when refining substance misuse treatment programs? Drug Alcohol Rev. 2007; 26:17-23. PMid:17364832 http://dx.doi.org/10.1080/09595230601036952

[31] Bentler PM. On tests and indices for evaluating structural models. Pers Indiv Differ. 2007; 42:825-829. http://dx.doi.org/10.1016/j.paid.2006.09.024

[32] Raykov T. On the use of confirmatory factor analysis in personality research. Pers Indiv Differ. 1998; $24: 291-293$. http://dx.doi.org/10.1016/S0191-8869(97)00159-1

[33] $\mathrm{Hu} \mathrm{L}$, Bentler PM. Cutoff criteria for covariance structure analysis: conventional criteria versus new alternatives. Struct Equ Modeling. 1999; 6:1-55. http://dx.doi.org/10.1080/10705519909540118

[34] Lau Y, Wang Y, Yin L, Chan KS, Guo X. Validation of the Mainland Chinese version of the Edinburgh Postnatal Depression Scale in Chengdu mothers. Int J Nurs Stud. 2010; 47:1139-1151. PMid:20219196 http://dx.doi.org/10.1016/j.ijnurstu.2010.02.005 
[35] Campbell DT, Fiske DW. Convergent and discriminant validation by the multitrait-multimethod matrix. Psychological Bulletin. 1959; 58:81-105. PMid:13634291 http://dx.doi.org/10.1037/h0046016

[36] Bentler PM. EQS structural equations program manual. Encino CA: Multivariate Software. 2006.

[37] Satorra A, Bentler PM. A scaled difference chi-square test statistic for moment structure analysis. Psychometrika. 2001; 66:507514. http://dx.doi.org/10.1007/BF02296192

[38] Kline PA. A psychometrics primer. London: Free Association Books. 2000.

[39] DiStefano C, Motl RW. Methodological artifact or substance? Examinations of wording effects associated with negatively worded items. In Structural Equation Modeling in Educational Research: Concepts and Applications. T. Teo, MS. Khine, eds. The Netherlands: Sense Publishers, 2009; 59-78.

[40] Horan PM, DiStefano C, Motl RW. Wording effects in self-esteem scales: Methodological artifact or response style? Struct Equ Modeling. 2003; 10(3):435-455. http://dx.doi.org/10.1207/S15328007SEM1003_6

[41] Ye S. Factor structure of the General Health Questionnaire (GHQ-12): The role of wording effects. Pers Indiv Differ. 2009; 46:197-201. http://dx.doi.org/10.1016/j.paid.2008.09.027

[42] Musek J. A general factor of personality: evidence for the Big One in the five-factor model. J Res Pers. 2007; 41:1213-1233. http://dx.doi.org/10.1016/j.jrp.2007.02.003

[43] Löckenhoff CE, Sutin AR, Ferrucci L, Costa PT Jr. Personality traits and subjective health in the later years: The association between NEO-PI-R and SF-36 in advanced age is influenced by health status. J Res Pers. 2008; 42:1334-1346. http://dx.doi.org/10.1016/j.jrp.2008.05.006

[44] Berlin I, Singleton EG, Pedarriosse AM, Lancrenon S, Rames A, Aubin HJ, Niaura R. The Modified Reasons for Smoking Scale: factorial structure, gender effects and relationship with nicotine dependence and smoking cessation in French smokers. Addiction. 2003; 98:1575-1583. PMid:14616184 http://dx.doi.org/10.1046/j.1360-0443.2003.00523.x

[45] Chapman BP, Duberstrein PR, Sörensen S, Lyness JM. Gender differences in five factor model personality traits in an elderly cohort: extension of robust and surprising findings to an older generation. Pers Indiv Differ. 2007; 43:1594-1603. PMid:18836509 http://dx.doi.org/10.1016/j.paid.2007.04.028

[46] Leung DYP, Chan SSC, Jiang CQ, Lam TH. Providing smoking cessation services and its relationship with knowledge and attitudes: A comparison of the Guangzhou and Hong Kong nurses. Journal of Comparative Asian Development. 2009; 8: $179-205$. http://dx/doi.org/10.1080/15339114.2009.9678478

[47] Hausman JA. Mismeasured variables in econometric analysis: problems from the right and problems from the left. J Econ Perspect [Internet]. 2001; 15: 57-67. Available from: http:/www.jstor.org/stable/2696516?origin=JSTOR-pdf. http://dx.doi.org/10.1257/jep.15.4.57 